\title{
Testing the effect of bioturbation and species abundance upon discrete-depth individual foraminifera analysis
}

\author{
Bryan C. Lougheed ${ }^{1}$ and Brett Metcalfe $\mathrm{e}^{2,3}$ \\ ${ }^{1}$ Department of Earth Sciences, Uppsala University, Uppsala, Sweden \\ ${ }^{2}$ Department of Earth Sciences, Vrije Universiteit Amsterdam, Amsterdam, the Netherlands \\ ${ }^{3}$ Laboratory of Systems and Synthetic Biology, Department of Agrotechnology and Food Sciences, \\ Wageningen University \& Research, Wageningen, the Netherlands
}

Correspondence: Bryan C. Lougheed (bryan.lougheed@geo.uu.se)

Received: 29 July 2021 - Discussion started: 27 September 2021

Revised: 20 January 2022 - Accepted: 24 January 2022 - Published: 25 February 2022

\begin{abstract}
We used a single foraminifera enabled, holistic hydroclimate-to-sediment transient modelling approach to fundamentally evaluate the efficacy of discrete-depth individual foraminifera analysis (IFA) for reconstructing past sea surface temperature (SST) variability from deep-sea sediment archives, a method that has been used, amongst other applications, for reconstructing El Niño-Southern Oscillation (ENSO). The computer model environment allows us to strictly control for variables such as SST, foraminifera species abundance response to SST, as well as depositional processes such as sediment accumulation rate (SAR) and bioturbation depth (BD) and subsequent laboratory processes such as sample size and machine error. Examining a number of best-case scenarios, we find that IFA-derived reconstructions of past SST variability are sensitive to all of the aforementioned variables. Running 100 ensembles for each scenario, we find that the influence of bioturbation upon IFAderived SST reconstructions, combined with typical samples sizes employed in the field, produces noisy SST reconstructions with poor correlation to the original SST distribution in the water. This noise is especially apparent for values near the tails of the SST distribution, which is the distribution region of particular interest in the case of, e.g. ENSO. The noise is further increased in the case of increasing machine error, decreasing SAR and decreasing sample size. We also find poor agreement between ensembles, underscoring the need for replication studies in the field to confirm findings at particular sites and time periods. Furthermore, we show that a species abundance response to SST could in theory bias IFA-derived SST reconstructions, which can have con-
\end{abstract}

sequences when comparing IFA-derived SST distributions from markedly different mean climate states. We provide a number of idealised simulations spanning a number of SAR, sample size, machine error and species abundance scenarios, which can help assist researchers in the field to determine under which conditions they could expect to retrieve significant results.

\section{Introduction}

\subsection{Background}

One of the most studied palaeoclimate signal carrier vessels within deep-sea sediment cores is the carbonate shells of planktonic foraminifera (microscopic, single-celled organisms), which can record the conditions of the ambient water that the foraminifera lived in. These organisms have a lifespan of $\sim 1$ month, after which their shells sink to, and are deposited on, the seafloor. Their short lifespan means that foraminifera microfossil populations retrieved from deep-sea sediment archives can, in principle, reflect past monthly sea surface temperature (SST) dynamics, which is key for reconstructing decadal scale climate processes, such as El NiñoSouthern Oscillation (ENSO). However, the technical limits associated with isotope ratio mass spectrometry analysis of foraminifera has traditionally required that many tens of single foraminifera shells are combined to produce a viable measurement, thus averaging out any monthly SST signal. Advances in mass spectrometry have allowed the analysis of 
single foraminifera shells sizes typically found in planktonic populations (Oba and Uomonoto, 1989; Spero and Williams, 1990), which has encouraged researchers to carry out a method commonly referred to as individual foraminifera analysis (IFA) to reconstruct SST variability associated with, e.g. ENSO (Koutavas et al., 2006; Leduc et al., 2009). This method can, in principle, allow for the extraction of a range of monthly SST values from a given interval of a deep-sea sediment archive (i.e. $1 \mathrm{~cm}$ discrete depths from a given sediment core). Using the IFA method, a number of foraminifera are subsampled from a discrete-depth foraminifera population, after which some form of SST proxy method is applied to each foraminifera's carbonate shell to infer individual SST values. Subsequently, an SST distribution can be inferred and used to indicate past SST variability.

The IFA method depends on a major assumption, namely that the SST distribution generated from the subsampled foraminifera is a faithful representation of the true distribution of monthly water SST values for a given time interval (i.e. a decadal/centennial/millennial period). However, the ability of discrete-depth IFA to accurately reproduce a time period's true water SST distribution can be clouded by a number of environmental, biological and logistical issues, which can occur in the water domain (predeposition), sediment archive domain (postdeposition) and laboratory domain (postretrieval).

\subsection{Challenges in the water domain}

Regarding issues in the water domain, it is possible that a foraminifera species may not continually inhabit a single surface water location or water depth, thus giving a noncontinuous record of SST, which can have consequences for, e.g. ENSO reconstructions (Roche et al., 2018; Metcalfe et al., 2020). Secondly, a species' abundance through time is not constant and can be influenced by SST itself, which may bias IFA-derived SST distribution reconstructions, which is especially relevant in the case of ENSO, which itself influences SST. Similarly, long-term absolute shifts in the overall range of SST (e.g. from a glacial to an interglacial world) may cause the water's SST range to shift from one that partially overlaps with a species' preferred temperature range to one that fully overlaps with a species' preferred temperature range. In practical terms, this could lead to an IFAderived artefactual shift from a relatively narrow apparent SST distribution to a relatively wider apparent SST distribution, with potential for incorrect interpretation regarding glacial-interglacial SST dynamics.

\subsection{Challenges in the sediment domain}

Issues associated with the sediment archive domain can further cloud IFA-derived SST distributions. Specifically, systematic bioturbation of deep-sea sediment archives means that individual foraminifera with vastly different ages are mixed into single discrete-depth sediment intervals, which is a particular challenge in the current state of the art in IFA, which still relies on the average age of a particular sediment interval (i.e. it is not yet feasible to decouple single planktonic foraminifera from their discrete depth by systematically dating individual specimens). This practical limitation in turn places an interpretive constraint upon IFA; when foraminifera from vastly different long-term climate states (i.e. multimillennial) are mixed into the same sediment interval, the IFA-derived SST variability reconstructed from that sediment interval cannot be exclusively assigned to decadal or centennial changes in interannual and intra-annual SST variability (Killingley et al., 1981). For these reasons, it is important to understand the age distribution of foraminifera contained within a discrete-depth sediment interval. For example, it is often assumed that a sediment archive with a sediment accumulation rate (SAR) of, e.g. $5 \mathrm{~cm} \mathrm{kyr}^{-1}$ will have a temporal resolution of $1000 / 5=200 \mathrm{yr} \mathrm{cm}^{-1}$. This assumption is deceptively supported by the observation that the mean age of such a sediment archive increases by $\sim 200 \mathrm{yr} \mathrm{cm}^{-1}$. However, downcore increase of discretedepth mean age is not the same concept as discrete-depth age variance. The distribution of the age contained within a single centimetre of sediment core is governed not only by the SAR, but also by the bioturbation depth (BD), the uppermost depth of the sediment within which bottom dwelling organisms actively mix the sediment. Following established understanding of bioturbation processes (Berger and Heath, 1968; Pisias, 1983; Schiffelbein, 1984), the $1 \sigma$ age value for a single $\mathrm{cm}$ of sediment core can be approximated, in the example of a $5 \mathrm{~cm} \mathrm{kyr}^{-1}$ sediment core with a representative BD of $10 \mathrm{~cm}$ (Boudreau, 1998), as 10/5 × 1000 $=2000$ years. In idealised conditions, the corresponding shape of the age distribution for a discrete-depth interval of sediment core will be characterised by an exponential distribution with long tail towards older ages. The average age of the sediment at the top of the sediment archive will also be similar to the $1 \sigma$ age value, as exhibited in ${ }^{14} \mathrm{C}$ dates of deep-sea core tops which support a BD of between 5 and $10 \mathrm{~cm}$ (Trauth et al., 1997; Henderiks et al., 2002), including for the Pacific (Peng et al., 1979; White et al., 2018). It is additionally important to consider the shape of this distribution when comparing IFAderived SST from an interval of sediment core (subsampled from a population with a exponential age distribution with a long tail towards older ages) to observational or model SST from specific periods of climate history (i.e. a uniform interval of time).

\subsection{Analytical challenges}

Finally, issues in the laboratory domain, such as sample size and analytical error, can serve to reduce the reproducibility of the reconstructed SST distribution and cause interpretive constraints (Killingley et al., 1981; Schiffelbein and Hills, 1984; Thirumalai et al., 2013; Fraass and Lowery, 2017; 
Dolman and Laepple, 2018; Lougheed, 2020). Some fields, such as foraminifera ecology, recommend a sample size of at least 300 specimens for sufficient reproducibility to capture an accurate picture of, e.g. species assemblage (Dryden, 1931; Patterson and Fishbein, 1989). In the case of IFA, the required sample size will be sensitive to the research question. For example, when reconstructing ENSO, sample sizes that are too small may lead to an interpretation based on insufficient data, i.e. brief climate intervals represented by single foraminifera may be oversampled or undersampled in the sample when compared to their true frequency of occurrence in history. These challenges highlight the need to carry out a simple modelling approach that incorporates conditions at a particular location (SAR, BD, sample size), which can be done either before or following sample collection.

\section{Method}

\subsection{Experimental design}

A computer modelling approach is used, which uniquely allows all parameters to be known and strictly controlled, thereby allowing us to create an idealised experimental design with minimised degrees of freedom. Such an approach offers advantages over field-based testing of IFA, where multiple dynamic parameters are unknown, thus leading to increased degrees of freedom and limiting the ability to make interpretative conclusions about the influence of isolated parameters. Our comprehensive modelling approach incorporates quantitative parameterisations of climate, sediment and laboratory processes. Such a controlled computer model environment allows us to directly compare a known input water SST distribution to a reconstructed SST distribution derived from the corresponding simulated sediment-based IFA. In this way, we can objectively quantify how well discretedepth IFA functions in a number of strictly controlled, bestcase scenarios, allowing its interpretive capacity for the reconstruction of decadal scale SST variability to be evaluated at the most fundamental level.

\subsection{Approach synopsis and model set-up}

We carry out a holistic hydroclimate-to-sediment transient modelling approach to test the suitability of discrete-depth IFA for the reconstruction of SST variability. Crucially, our approach includes a quantified representation of both sediment processes (in particular bioturbation) and species abundance, thus building upon previous models and simulation estimations of IFA accuracy where such information was not yet included (Leduc et al., 2009; Thirumalai et al., 2013; Fraass and Lowery, 2017). Our modelling approach is carried out using an offline coupling of two transient models: a single-foraminifera sediment accumulation simulator (SEAMUS; Lougheed, 2020) run at a monthly timestep resolution, forced with monthly SST from the TRACE-21ka cli- mate model (He, 2011). We investigate a number of bestcase scenarios, concentrating on the time period spanning from $20 \mathrm{ka}$ (BP 1950) up to and including $1989 \mathrm{CE}$, assuming a hypothetical sediment core location (Fig. 1) at the centre of the Niño 3.4 ENSO region that is used to calculate the Oceanic Niño Index. While the TRACE-21ka climate model does not necessarily fully capture ENSO processes, we choose this location in the model because of its dynamic SST (Fig. 1), which make it an interesting location to test how inputted monthly SST is reconstructed by the simulated IFA method. In reality it may or may not be possible to retrieve a foraminifera-rich sediment core from this site, but here for the purposes of this theoretical best-case modelling scenario, we assume that it would be possible.

In this study, simulated single foraminifera are incorporated into synthetic sediment archives, the latter of which employ best-case sedimentation conditions whereby representative values for SAR and BD are both kept temporally constant. We assume a best-case scenario where foraminifera perfectly record monthly SST (in this case the TRACE-21ka SST), and we also assume the existence of an ideal proxy method that allows perfect retrieval of SST data from the single foraminifera. In reality, foraminifera may not continuously record the water temperature at the surface or indeed at the same water depth in general, which further complicates IFA reconstructions of SST dynamics in practice; however, here we seek to test best-case conditions. After carrying out the sediment archive and bioturbation simulation, synthetic single foraminifera are randomly picked from each discretedepth $\mathrm{cm}$ interval of the simulated core, thereby resulting in virtual IFA. The output of the best-case virtual IFA retrieved from the sediment depth domain can subsequently be directly compared to the inputted SST in the time domain (i.e. TRACE-21ka SST), allowing us to evaluate the current state of the art in IFA at the most fundamental level.

We summarise the sediment model component (SEAMUS) in Sect. 2.3, and the climate component (TRACE$21 \mathrm{ka}$ ) in Sect. 2.4. An overview of our various best-case scenario simulations, as well as their associated run parameters, can be found in Sect. 2.5.

\subsection{Sediment model component}

We model the sedimentation history of single foraminifera using the SEAMUS sediment accumulation model (Lougheed, 2020). This stochastic model uses the same established understanding of bioturbation (Berger and Heath, 1968; Pisias, 1983; Bard, 2001) that is also incorporated into previous sediment accumulation models (Trauth, 1998, 2013; Dolman and Laepple, 2018), but differs in model execution in that it is explicitly designed for the purpose of modelling single foraminifera, thus making it a suitable sediment model for use in this IFA evaluation study. Furthermore, the stochastic nature of the model, combined with an ensemble approach, is ideal for simulating 


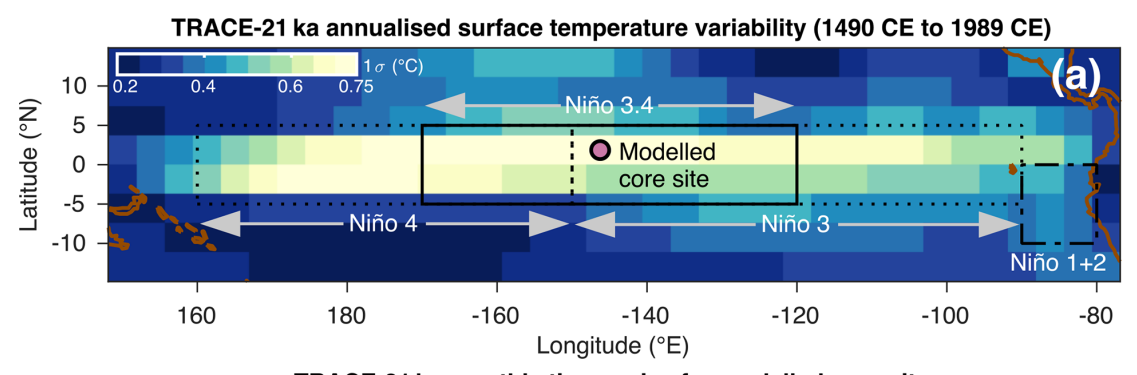

TRACE-21 ka monthly time series for modelled core site

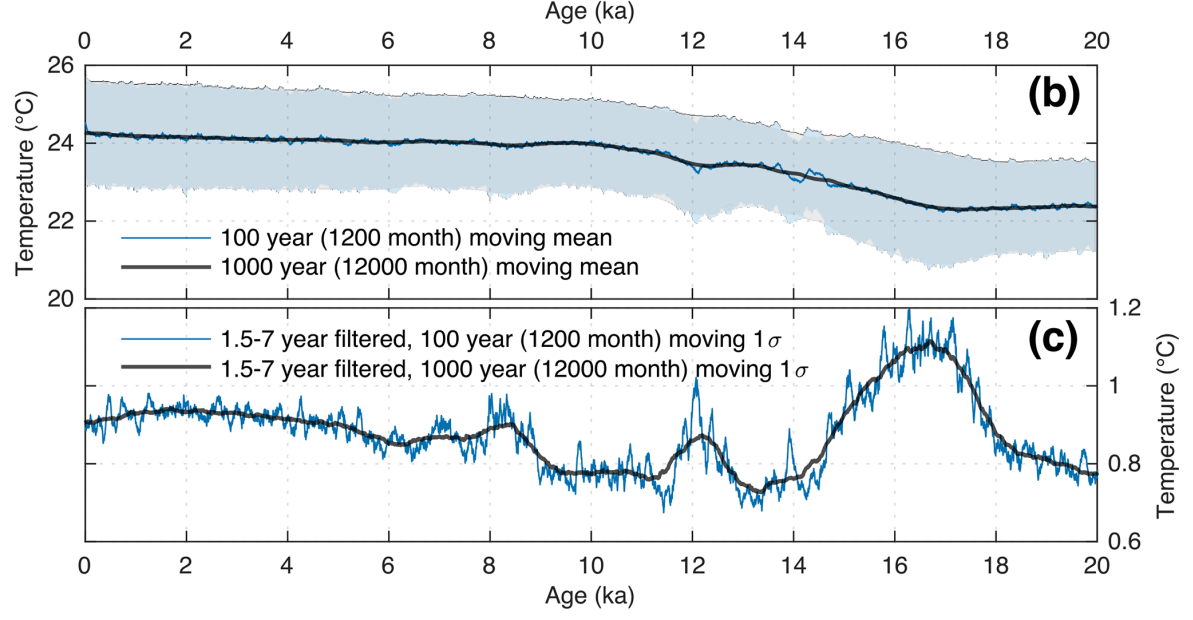

Figure 1. Overview of the modelled core site location and associated TRACE-21ka data. (a) The location of the modelled sediment core site superimposed upon the standard deviation of annualised SST from the TRACE-21ka for the 500 year period between $1490 \mathrm{CE}$ and $1989 \mathrm{CE}$. Also shown for reference are the Niño regions $1+2,3,3.4$ and 4. (b) 100 year (1200 month) and 1000 year (12000 month) moving mean of the monthly TRACE-21ka SST data for the modelled sediment core site. Also shown in light blue and light grey are the moving $\pm 1 \sigma$ envelopes associated with the moving 100 year (1200 month) and 1000 year (12000 month) windows, respectively. (c) 100 year (1200 month) and 1000 year (12000 month) moving $1 \sigma$ of the 1.5-7 year filtered monthly SST data.

bioturbation of single foraminifera, which is in itself a stochastic process. Furthermore, this bioturbation model is capable of receiving temporally dynamic input for all parameters. Our period of interest spans from $20 \mathrm{ka}$ to $1989 \mathrm{CE}$, so we have run the SEAMUS model from $30 \mathrm{ka}$ to $1989 \mathrm{CE}$ to provide sufficient model spin-up for our period of interest. The model is run here using a monthly timestep resolution (to match the timestep resolution of TRACE-21ka), whereby single synthetic foraminifera are generated at each monthly timestep and added to the top of the sediment archive after which the $\mathrm{BD}$ of the sediment archive is uniformly mixed. All simulations are run with an appropriate $\mathrm{BD}$ of $10 \mathrm{~cm}$, following previous studies (Boudreau, 1998). Some of our model run scenarios assume a temporally constant foraminiferal abundance, in such cases we assign a constant per timestep foraminifera abundance that results in $10^{4}$ foraminifera per centimetre of sediment (i.e. the prescribed per timestep abundance is higher in the case of higher SAR and vice versa). In the case of model runs with temporally dynamic foraminifera abundance, the amount of foraminifera per centimetre that will result in 100 foraminifera per timestep (i.e. month) for the given SAR is simulated, allowing temporal (i.e. monthly) changes in abundance to be modelled with sufficient statistical power (i.e. if relative abundance of the species drops from 0.56 to 0.55 then it will result in one less foraminifera of the species being simulated for a timestep). All of our model run scenarios are carried out using 100 ensemble runs in SEAMUS, thus fully capturing (for 100 percentiles) the stochastic nature of bioturbation (i.e. the fact that no two sediment archives formed under the same conditions will be exactly alike). Subsequently, four separate randomised picking scenarios are carried out on each of the 100 ensembles, whereby $50,100,500$ or $10^{4}$ synthetic foraminifera are randomly picked from each discrete $1 \mathrm{~cm}$ depth slice of the synthetic core, whereby the picker is assumed to have perfectly identified the species in all cases, thus avoiding challenges associated with species misidentification (Pracht et al., 2019). The $10^{4}$ picking scenario is intentionally included as an unrealistically large sample size, essentially acting as a reference scenario virtually free of sample size noise. Finally, in some scenarios we add Gaussian noise of $\pm 1^{\circ} \mathrm{C}$ to the SST of all simulated foraminifera, to mimic proxy uncertainty. All ensemble runs were performed using 
a Linux computer cluster provided by the Swedish National Infrastructure for Computing (SNIC) at the Uppsala Multidisciplinary Centre for Advanced Computational Science (UPPMAX).

\subsection{Climate model component}

Monthly SST forcing for the SEAMUS model is sourced from the TRACE-21ka transient climate simulation ( $\mathrm{He}$, 2011), specifically using the surface temperature data for the TRACE-21ka grid cell centred on the coordinates $1.86^{\circ} \mathrm{N}$ and $146.25^{\circ} \mathrm{W}$. This grid cell, at the centre of the Niño 3.4 ENSO region used for calculating the Oceanic Niño Index, is ideal for our synthetic core simulation as it is characterised by large variation in the model's interannual seasonal surface temperature (Fig. 1a), somewhat analogous to, e.g. ENSO. Furthermore, the grid cell also captures the glacial-interglacial SST transition (Fig. 1b), as well as typical TRACE-21ka transient changes in ENSO-like SST variability, as shown by the 1.5-7 year filtered 100 and 1000 year moving $1 \sigma$ of SST (Fig. 1c). This filtering approach has previously been used to identify ENSO-like variability in TRACE-21ka for the Niño 3.4 region (Liu et al., 2014). While the model variability is itself of course not a true replication of the real ENSO signal, it nonetheless offers an interesting analogous time series of interannual changes in SST variability with which to test the efficacy of the IFA method in reproducing said SST variability.

The TRACE-21ka dataset is the result of a fully coupled Community Climate System Model (CCSM3) simulation with T31_gx3 grid resolution that uses transient forcing changes in both greenhouses gases, orbitally driven insolation variations, ice sheet evolution (ICE-5G) and associated meltwater fluxes for a non-accelerated atmosphere-ocean-sea ice-land surface coupling. The TRACE-21ka dataset begins at $22 \mathrm{ka}$, whereas our SEAMUS run starts at $30 \mathrm{ka}$. The reason for this difference is that we provide an extra $10 \mathrm{kyr}$ of spin-up time for the SEAMUS model, which is important in cases of very low SAR (e.g. $\leq 5 \mathrm{~cm} \mathrm{kyr}^{-1}$ ). In order to provide SST data for synthetic foraminifera generated between 30 and $22 \mathrm{ka}$, the oldest 1500 years contained within the TRACE-21ka dataset are repeated from 22 to $30 \mathrm{ka}$. Such an approach obviously does not represent an accurate picture of the climate between 30 and $22 \mathrm{ka}$, but it has no practical consequences for the particular purpose of our study, which is to compare a given climate input signal in the time domain to the subsequent signal recorded by single foraminifera in the sediment depth domain. Furthermore, our period of study interest spans the past $20 \mathrm{kyr}$.

\subsection{Model run settings}

We carry out a number of best-case scenarios, with each scenario being subject to 100 ensemble runs to capture the full stochastic range resulting from the sedimentation, bio-

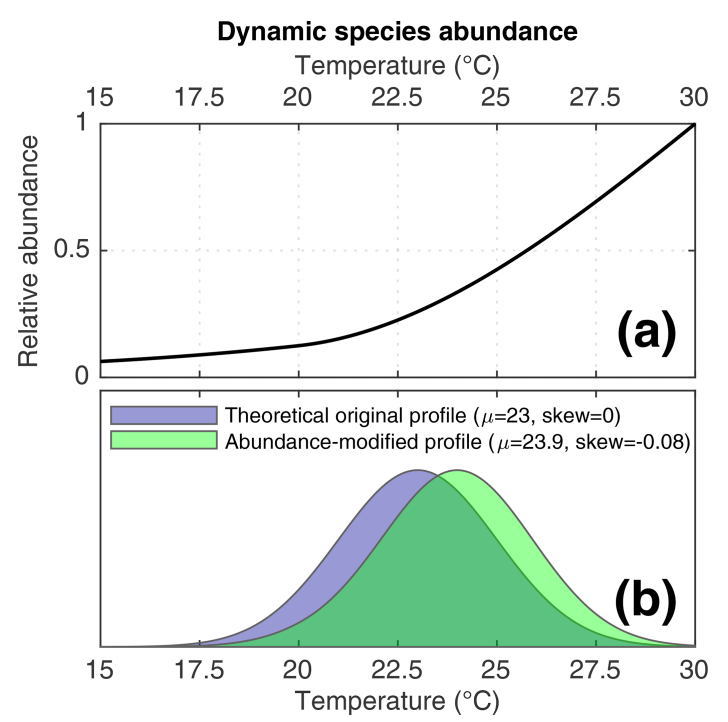

Figure 2. (a) The dynamic species abundance function applied to some of the simulations in this study. (b) A theoretical example of how the dynamic species abundance would bias recording of SST by individual foraminifera. In purple, a normally distributed theoretical SST profile. In green, the signal that would be recorded by a species affected by the dynamic species abundance function.

turbation and picking processes. We run SAR scenarios for 5,10 and $40 \mathrm{~cm} \mathrm{kyr}^{-1}$. In the figures in the main text, we concentrate on the $10 \mathrm{~cm} \mathrm{kyr}^{-1}$ scenarios only. The corresponding figures for the 40 and $5 \mathrm{~cm} \mathrm{kyr}^{-1}$ scenarios, the latter of which may be more realistic for many parts of the Pacific, can be found in the Supplement. Each of the three SAR scenarios is first subjected to 100 ensemble runs with constant foraminifera abundance and a perfect SST proxy, a second set of 100 ensemble runs is then carried out with constant abundance and added $\pm 1{ }^{\circ} \mathrm{C}$ Gaussian noise on the SST proxy, a third set of 100 ensemble runs is carried out with dynamic abundance and a perfect SST proxy and a final set of 100 ensemble runs is carried out with dynamic abundance and $\pm 1{ }^{\circ} \mathrm{C}$ Gaussian noise on the SST proxy. All of the aforementioned 1200 ensembles are each subjected to randomised picking for $50,100,500$ and $10^{4}$ foraminifera per centimetre of sediment core depth.

As described in the previous paragraph, some of our scenarios incorporate dynamic foraminifera abundance in order to investigate the effect of changes in species abundance upon IFA-derived reconstructions. In these scenarios, we use a hypothetical transfer function (Fig. 2a) to assign a per timestep abundance to our simulated foraminifera species. This theoretical transfer function is purely demonstrational and is used to gain insights into how a given abundance response influences IFA reconstructions of SST variability. Timestep abundance is calculated by applying the function to the corresponding TRACE-21ka SST for the timestep. This approach allows us to quantify how a known species abun- 


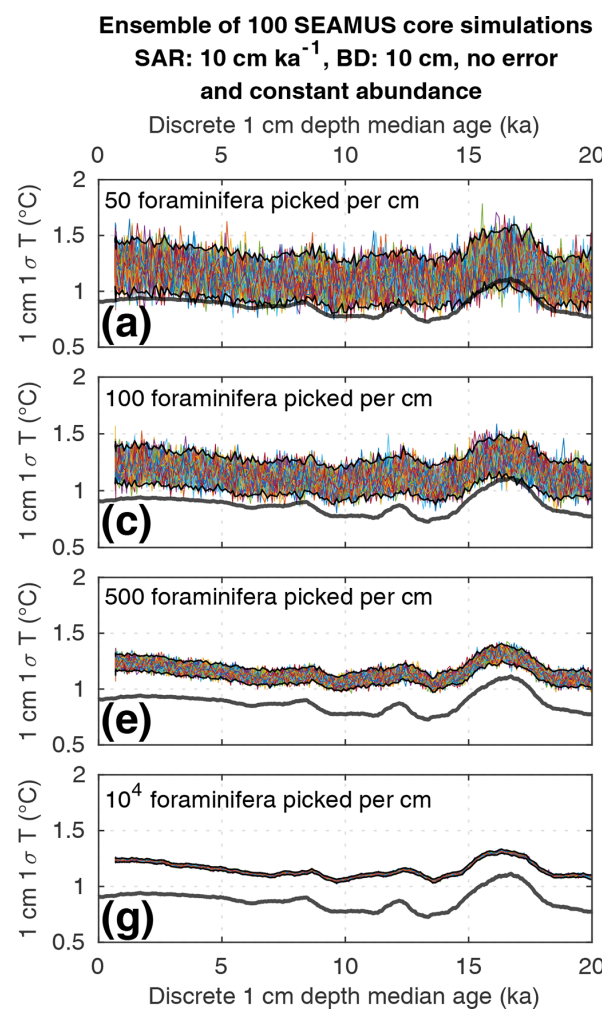
Ensemble of 100 SEAMUS core simulations
SAR: $10 \mathrm{~cm} \mathrm{ka}{ }^{-1}$, BD: $10 \mathrm{~cm}, \pm 1^{\circ} \mathrm{C}$ error and constant abundance
Discrete $1 \mathrm{~cm}$ depth median age (ka)
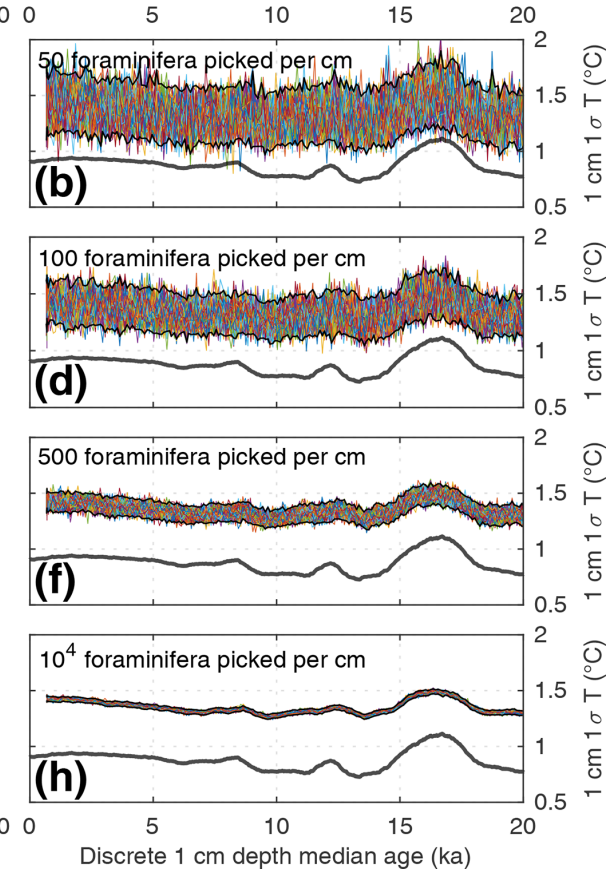

Figure 3. Simulated downcore, discrete $1 \mathrm{~cm}$ depth $1 \sigma$ SST values of simulated single foraminifera from various $10 \mathrm{~cm} \mathrm{kyr}^{-1} \mathrm{SAR}$ scenarios with $10 \mathrm{~cm} \mathrm{BD}$, each with 100 ensembles of SEAMUS runs. In each panel, each ensemble is shown using a coloured line. The solid black lines represent the $95 \%$ interval of the ensemble runs at each discrete $1 \mathrm{~cm}$ depth. Also shown for reference as a thick grey line is the 1000 year (12000 month) moving $1 \sigma$ of the 1.5-7 year filtered monthly SST data (as also shown in Fig. 1c). The left panels (a, c, e, g) show the output of scenarios with 50,100, 500 and $10^{4}$ randomly picked foraminifera per discrete $1 \mathrm{~cm}$ depth, all with constant species abundance and no assumed analytical error. The right panels $(\mathbf{b}, \mathbf{d}, \mathbf{f}, \mathbf{h})$ show the output of scenarios with $50,100,500$ and $10^{4}$ randomly picked foraminifera per discrete $1 \mathrm{~cm}$ depth, all with constant species abundance and an assumed analytical error of $\pm 1{ }^{\circ} \mathrm{C}$ in SST.

dance response to SST could systematically bias an IFAderived SST distribution. Consider, for example, a theoretical time interval whereby the true monthly SST data are normally distributed, as in the theoretical example in Fig. 2b. In such a case, an IFA-derived SST distribution using a species characterised by our SST transfer function would be biased towards warmer temperatures and, furthermore, the shape of the IFA-derived SST distribution would be skewed, as shown in the abundance-modified profile in Fig. $2 b$.

\section{Results \& discussion}

\subsection{Downcore, discrete-depth IFA standard deviation}

Numerous studies have concentrated on subsampling numerous individual foraminifera from the same discrete-depth interval of a sediment core, from which the $1 \sigma$ value of the SST (or a proxy equivalent thereof) of those foraminifera is calculated to infer SST variability for a particular time period, whereby a greater $1 \sigma$ value is assumed to indicate increased SST variability due to, e.g. ENSO (Koutavas et al., 2006;
Koutavas and Joanides, 2012; Rustic et al., 2015). To evaluate such an approach, we compare the 1.5-7 year filtered 1000 year moving $1 \sigma$ of SST in the time domain (Fig. 1c) to ensembles of SEAMUS runs carried out under various sediment and picking conditions within a $10 \mathrm{~cm} \mathrm{kyr}^{-1}$ scenario (Figs. 3 and 4). The equivalent figures for the 40 and $5 \mathrm{~cm} \mathrm{kyr}^{-1}$ scenarios, the latter of which may be more representative for the open ocean areas of the Pacific (Olson et al., 2016; Metcalfe et al., 2020), can be found in the Supplement.

We find that the discrete-depth, downcore $1 \sigma$ value reconstructed using IFA analysis for the simulated $10 \mathrm{~cm} \mathrm{kyr}^{-1}$ scenarios varies greatly between all of the 100 ensemble runs in the case of IFA sample sizes typically used in the field, i.e. between 50 foraminifera (Figs. 3a-b; $4 \mathrm{a}-\mathrm{b}$ ) and 100 foraminifera (Figs. 3c-d; 4c-d), individual foraminifera being picked per centimetre. This poor reproducibility between ensemble runs is a result of noise generated by small sample sizes in combination with systematic bioturbation. The practical consequence of this poor reproducibility is that, in the case of typical sample sizes used in the field (50-100 foraminifera), none or very few of the 100 ensemble runs re- 


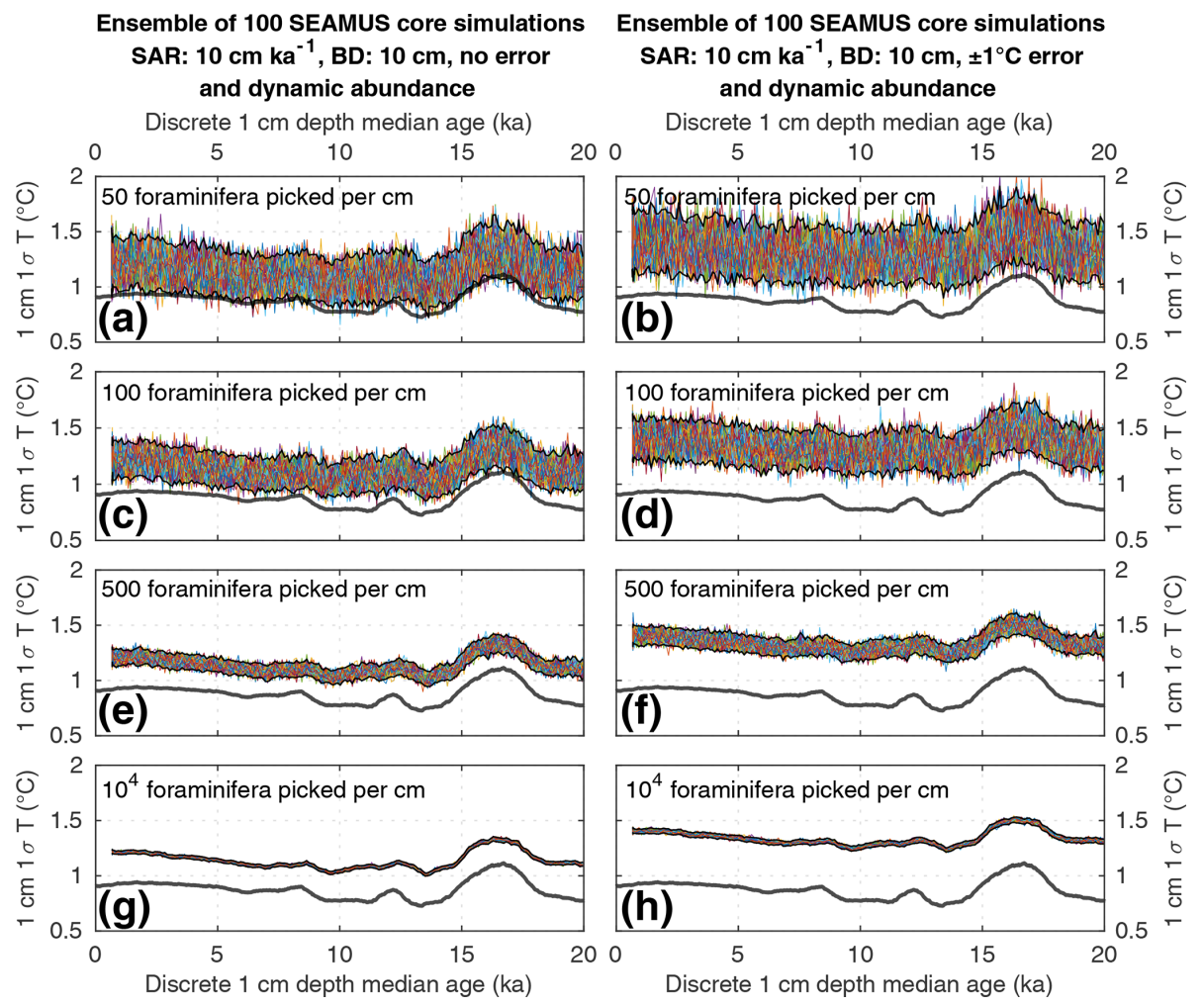

Figure 4. Simulated downcore, discrete $1 \mathrm{~cm}$ depth $1 \sigma$ SST values of simulated single foraminifera from various $10 \mathrm{~cm} \mathrm{kyr}^{-1} \mathrm{SAR}$ scenarios with $10 \mathrm{~cm} \mathrm{BD}$, each with 100 ensembles of SEAMUS runs. In each panel, each ensemble is shown using a coloured line. The solid black lines represent the $95 \%$ interval of the ensemble runs at each discrete $1 \mathrm{~cm}$ depth. Also shown for reference as a thick grey line is the 1000 year (12 000 month) moving $1 \sigma$ of the 1.5-7 year filtered monthly SST data (as also shown in Fig. 1c). The left panels (a, c, e, $\mathbf{g}$ ) show the output of scenarios with 50,100, 500 and $10^{4}$ randomly picked foraminifera per discrete $1 \mathrm{~cm}$ depth, all with dynamic species abundance (following Fig. 2a) and no assumed analytical error. The right panels (b, d, f, h) show the output of scenarios with 50, 100, 500 and $10^{4}$ randomly picked foraminifera per discrete $1 \mathrm{~cm}$ depth, all with dynamic species abundance (following Fig. 2a) and an assumed analytical error of $\pm 1^{\circ} \mathrm{C}$ in SST.

sult in a significant and strong correlation between the IFAderived downcore $1 \sigma$ SST signal and the 1.5-7 year filtered TRACE-21 ka 1000 year moving $1 \sigma$ (Table 2 ), for the period 18 to $12 \mathrm{ka}$, a period of dynamic ENSO-like variation in the TRACE-21ka SST. We define a significant and strong correlation here as $r^{2} \geq 0.6$ and $p \leq 0.05(\alpha=5 \%)$, i.e. that the correlation is strong enough such that $60 \%$ of the variation is shared between the two variables, with significance defined using an $\alpha$ of $5 \%$. Furthermore, the wide $95.4 \%$ band of ensemble downcore $1 \sigma$ SST values demonstrates a practical challenge for studies that compare decadal and centennial SST variability from two distinct time periods by comparing, e.g. a late glacial sediment slice $1 \sigma$ SST value to a late Holocene sediment slice $1 \sigma$ SST value. In such cases, our model results suggest that for the aforementioned typical sample sizes deployed in the field (50-100 foraminifera), random chance may lead to any number of possible apparent outcomes regarding the relative apparent SST variability of the late glacial and the late Holocene sediment slices.
We do find, however, that greatly increased sample size, higher SAR and reduced measurement error can all significantly improve the probability of a given ensemble's IFAderived downcore $1 \sigma$ SST exhibiting significant correlation with the TRACE-21ka SST variation (Table 2). We must stress, however, that our best-case scenarios involve constant SAR and BD, whereas real-world conditions in the field are inherently dynamic and would, therefore, be more challenging. Additionally, we note that the improved correlation in the case of larger samples size does not correspond to a good reproduction of the absolute values of the SST variation as indicated by the TRACE-21ka SST ENSO-type variation. Even in the case of an extreme best-case scenario where it is possible to find, pick and analyse $10^{4}$ foraminifera per centimetre, the absolute values of the ENSO-type variation derived from IFA are systematically greater than that of the TRACE-21ka SST ENSO-type variation (Figs. $3 \mathrm{~g}$ and $4 \mathrm{~g}$ ), despite good correlation (Table 2). This offset in absolute values can be due to the fact that the 1.5-7 year filtered, 1000 year smoothed TRACE-21ka standard deviation is re- 
Table 1. Overview of SAR and number of picked specimens in select IFA studies (including non-ENSO studies). Region codes are as follows: WEP - western equatorial Pacific; CEP - central equatorial Pacific; EEP - eastern equatorial Pacific; EEI - eastern equatorial Indian Ocean; SIO - southern Indian Ocean; ARA - Arabian Sea. We have estimated the $1 \sigma$ value of age in $1 \mathrm{~cm}$ of sediment based on the SAR and a BD of $10 \mathrm{~cm}$ (Boudreau, 1998), using the following calculation based on (Berger and Heath, 1968): BD/SAR $\times 1000$, where SAR is entered in $\mathrm{cm} \mathrm{kyr}^{-1}$ and BD in $\mathrm{cm}$.

\begin{tabular}{|c|c|c|c|c|c|}
\hline Core(s) & Study & Region & $\begin{array}{r}\text { Approximate } \\
\text { SAR } \\
\left(\mathrm{cm} \mathrm{kyr}^{-1}\right)\end{array}$ & $\begin{array}{l}\text { Estimated } 1 \sigma \\
\text { value of age } \\
\text { in } 1 \mathrm{~cm}(\mathrm{yr})\end{array}$ & $\begin{array}{r}\text { Specimens picked } \\
\text { per discrete } \\
\text { interval }(\#)\end{array}$ \\
\hline MGL1208-14MC and 12GC & White et al. (2018) & CEP & $\sim 2.5$ & 4000 & $70-90$ \\
\hline ODP 806 & Ford et al. (2015) & WEP & $\sim 3$ & 3300 & $60-70$ \\
\hline ODP 849 & $\begin{array}{l}\text { Ford et al. (2015), } \\
\text { White and Ravelo (2020) }\end{array}$ & EEP & $\sim 4$ & 2500 & $60-70$ \\
\hline KNR195-5 MC42 & Rustic et al. (2015) & EEP & $\sim 12$ & 830 & 55 \\
\hline MD02-2529 & Leduc et al. (2009) & EEP & $\sim 40$ & 250 & $65-90$ \\
\hline V21-30 & $\begin{array}{l}\text { Koutavas et al. (2006), } \\
\text { Koutavas and Joanides (2012) }\end{array}$ & EEP & $\sim 12$ & 830 & 50 \\
\hline MD98-2177 & Khider et al. (2011) & WEP & $\sim 70$ & 150 & $60-90$ \\
\hline SO189-119KL & Thirumalai et al. (2019) & EEI & $\sim 20$ & 500 & $55-65$ \\
\hline SO189-39KL & Thirumalai et al. (2019) & EEI & $\sim 37$ & 270 & $55-65$ \\
\hline GeoB 10038-4 & Thirumalai et al. (2019) & EEI & $\sim 9$ & 1100 & $55-65$ \\
\hline GeoB 10053-7 & Thirumalai et al. (2019) & EEI & $\sim 35$ & 290 & $55-65$ \\
\hline NIOP 905P & Ganssen et al. (2011) & ARA & $\sim 20$ & 500 & $30-40$ \\
\hline 64PE-174P13 & Scussolini et al. (2013) & SIO & $\sim 1.2$ & 8330 & $20-30$ \\
\hline
\end{tabular}

flecting a different integration of the time than the $1 \sigma$ data retrieved from discrete-depth IFA. The former is based on a smoothing of uniform time, whereas the latter represents a population of foraminifera with a long-tailed age distribution. The absolute offset between the two signals is further increased in the case of machine error on the IFA SST analysis (Figs. $3 \mathrm{~h}$ and $4 \mathrm{~h}$ ), thus highlighting the importance of accurately quantifying uncertainties in the analytical process.

\subsection{Discrete-depth IFA distribution analysis}

Many IFA studies have gone beyond studying discrete depth $1 \sigma$ SST values and have branched into more forensic studies of the shape of discrete depth SST distributions. These studies have focused on analysing the shape of said distribution using various statistical tools, including skewness analysis of histograms (Leduc et al., 2009; Khider et al., 2011), as well as quantile-quantile (Q-Q) plots (Ford et al., 2015; White et al., 2018; Thirumalai et al., 2019; Rongstad et al., 2020; White and Ravelo, 2020). Such analyses can reveal apparent shifts in the shape of the downcore IFA-derived SST distribution, which the aforementioned studies have attributed to SST changes in the water caused by ENSO-type climate variability.

Here, we compare the monthly TRACE-21ka SST data for the 18 to $17 \mathrm{ka}$ period to our 100 ensembles of simulated IFA SST for the $10 \mathrm{~cm} \mathrm{kyr}^{-1}$ scenario, taking the $1 \mathrm{~cm}$ discretedepth with a median age closest to $17.5 \mathrm{ka}$ in each ensemble. We show 100 ensembles with no analytical error and constant abundance (Fig. 5), 100 ensembles with $\pm 1^{\circ} \mathrm{C}$ analyt- ical error and constant abundance (Fig. 6), 100 ensembles with $\pm 1^{\circ} \mathrm{C}$ analytical error and dynamic abundance (Fig. 7), and 100 ensembles with $\pm 1^{\circ} \mathrm{C}$ analytical error and dynamic abundance (Fig. 8). In all cases in our $10 \mathrm{~cm} \mathrm{kry}^{-1}$ scenario, we find that sample sizes typically associated with IFA in the field (50-100 foraminifera, see Table 1) produce high levels of noise, leading to low reproducibility from one ensemble to the next (panels a and d in Figs. 5-8). As expected, the 5 and $40 \mathrm{~cm} \mathrm{kyr}^{-1}$ scenarios (see figures in the Supplement) result in lower and higher reproducibility, respectably. In practical terms, these results suggest that if one were to retrieve multiple sediment cores and carry out discrete-depth IFA at the same coring location, it is possible that different outcomes would be produced each time, each with suboptimal correspondence to the true SST distribution in the water. Furthermore, as the level of noise increases with lower SAR, one has to be additionally careful when comparing IFA results from sites with markedly different SAR.

We also find that the IFA method has a tendency for noisy oversampling or undersampling of the tails of the true SST distribution in the case of typical sample sizes (50-100 specimens) used in the field (panels $b$ and e in Figs. 5-8). This effect can be attributed to the fact that there is a low occurrence of individual foraminifera within the population that record more extreme SST, and small sample sizes are likely to either miss such foraminifera altogether (i.e. $-100 \%$ oversampling) or, in the case of a single such foraminifera being picked within the sample, significantly over-represent extreme SST within the sample (in some cases $>500 \%$ over- 

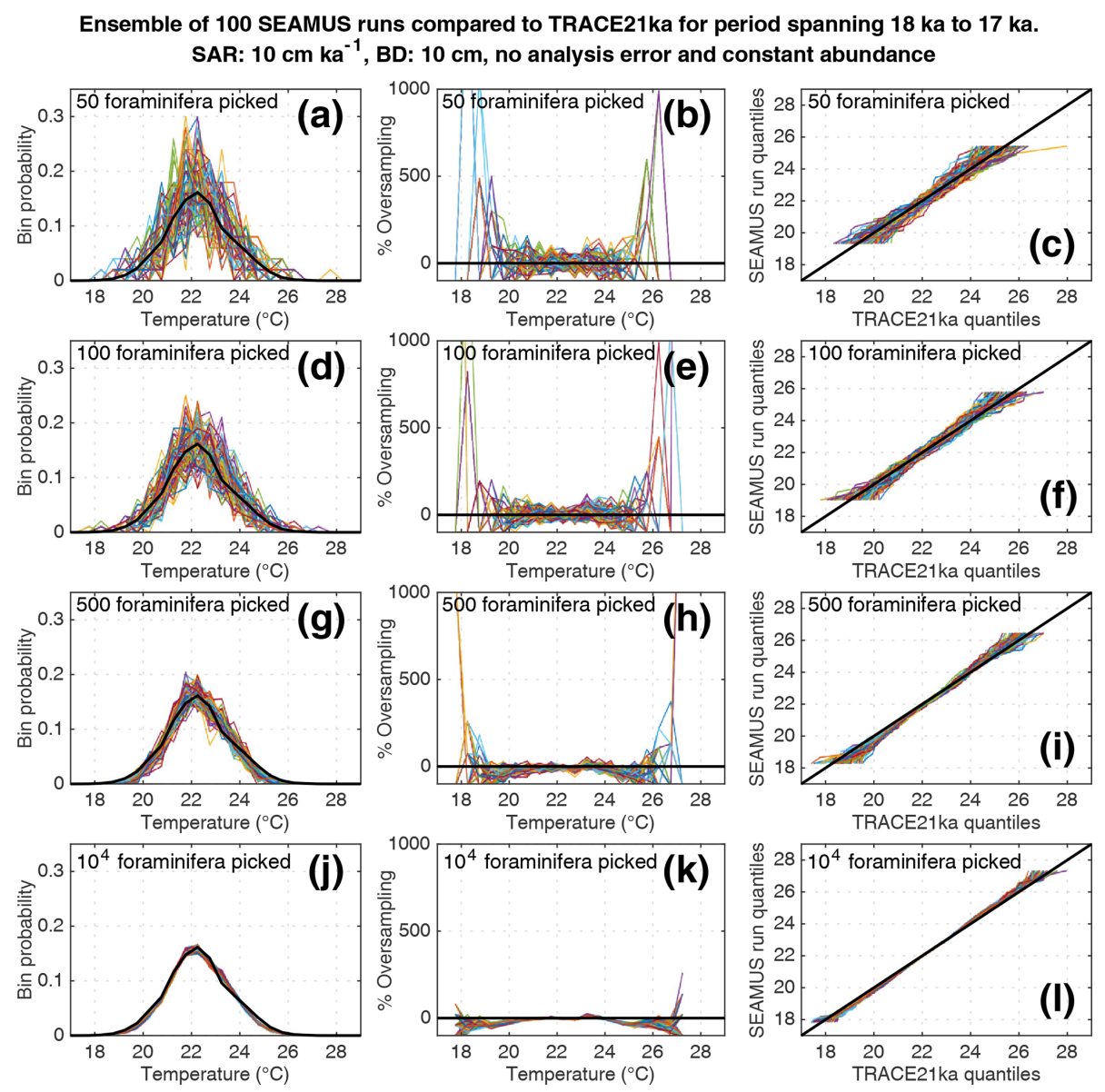

Figure 5. Simulated single foraminifera SST distributions from 100 ensembles of SEAMUS runs, with SAR of $10 \mathrm{~cm} \mathrm{kyr}^{-1}$, BD of $10 \mathrm{~cm}$, no analytical error and constant abundance. In each ensemble, the single foraminifera SST distribution from a single discrete depth with a simulated median age of $17.5 \mathrm{ka}$ is compared to the TRACE-21ka SST distribution for the 18 to $17 \mathrm{ka}$ period. The left panels $(\mathbf{a}, \mathbf{d}, \mathbf{g}, \mathbf{j})$ show the 100 SEAMUS ensembles as coloured lines in the case of 50,100, 500 and $10^{4}$ randomly picked foraminifera, with the TRACE-21ka SST distribution shown as a black line. The middle panels $(\mathbf{b}, \mathbf{e}, \mathbf{h}, \mathbf{k})$ show the rate of oversampling/undersampling for each of the 100 SEAMUS ensembles (coloured lines) relative to the TRACE-21ka SST distribution (black line) in the case of 50, 100, 500 and $10^{4}$ randomly picked foraminifera. The right panels $(\mathbf{c}, \mathbf{f}, \mathbf{i}, \mathbf{l})$ show Q-Q plots of the 100 SEAMUS ensemble quantiles vs. the TRACE-21ka quantiles as coloured lines in the case of 50,100, 500 and $10^{4}$ randomly picked foraminifera, with a perfect $1: 1$ correspondence to TRACE-21ka shown for reference as a black line.

sampling, i.e. an extreme SST is represented in the sample at five times the rate is occurs in reality). This effect has practical consequences for interpretations made within IFA studies, seeing as the tails of the SST distribution are the region of interest when reconstructing the presence of, e.g. extreme ENSO events (Koutavas et al., 2006; Rustic et al., 2015; Glaubke et al., 2021). This noisy under- or oversampling of the distribution tails by IFA also translates directly to sample Q-Q plots (panels c and $\mathrm{f}$ in Figs. 5-8), which are commonly used in IFA studies to investigate the population distribution (Ford et al., 2015; Rongstad et al., 2020). This level of noise in the tails increases substantially in the case of increased analytical error, i.e. when one compares panels (a)(f) in Fig. 5 (without simulated analysis error) and Fig. 6 (with $\pm 1^{\circ} \mathrm{C}$ simulated analysis error). We furthermore find that even larger sample sizes involving 500 foraminifera are prone to noisy undersampling or oversampling in the tails, especially in the case of analytical error (panels g, h, and i in Fig. 6). We also note that the tendency for undersampling and oversampling in the tails is greatly increased in the case of lower SAR and somewhat reduced in the case of higher SAR (see figures in the Supplement for 5 and $40 \mathrm{~cm} \mathrm{kyr}^{-1}$ SAR scenarios). Even in the case of sample sizes of $10^{4}$ foraminifera in our $10 \mathrm{~cm} \mathrm{kyr}^{-1}$ scenario (panels $\mathrm{j}, \mathrm{k}$ and 1 in Figs. 5 and 6) we also find suboptimal agreement with the TRACE-21ka SST distribution in the tails. This disagreement is not due to noise but due to the fact that we emulate the current state of the art, whereby model SST from a uniform interval of time (in our case 18 to $17 \mathrm{ka}$ ) is compared to a sample of foraminifera retrieved from sediment with a popu- 
Ensemble of 100 SEAMUS runs compared to TRACE21 ka for period spanning $18 \mathrm{ka}$ to $17 \mathrm{ka}$. SAR: $10 \mathrm{~cm} \mathrm{ka}{ }^{-1}, \mathrm{BD}: 10 \mathrm{~cm}, \pm 1^{\circ} \mathrm{C}$ analysis error and constant abundance
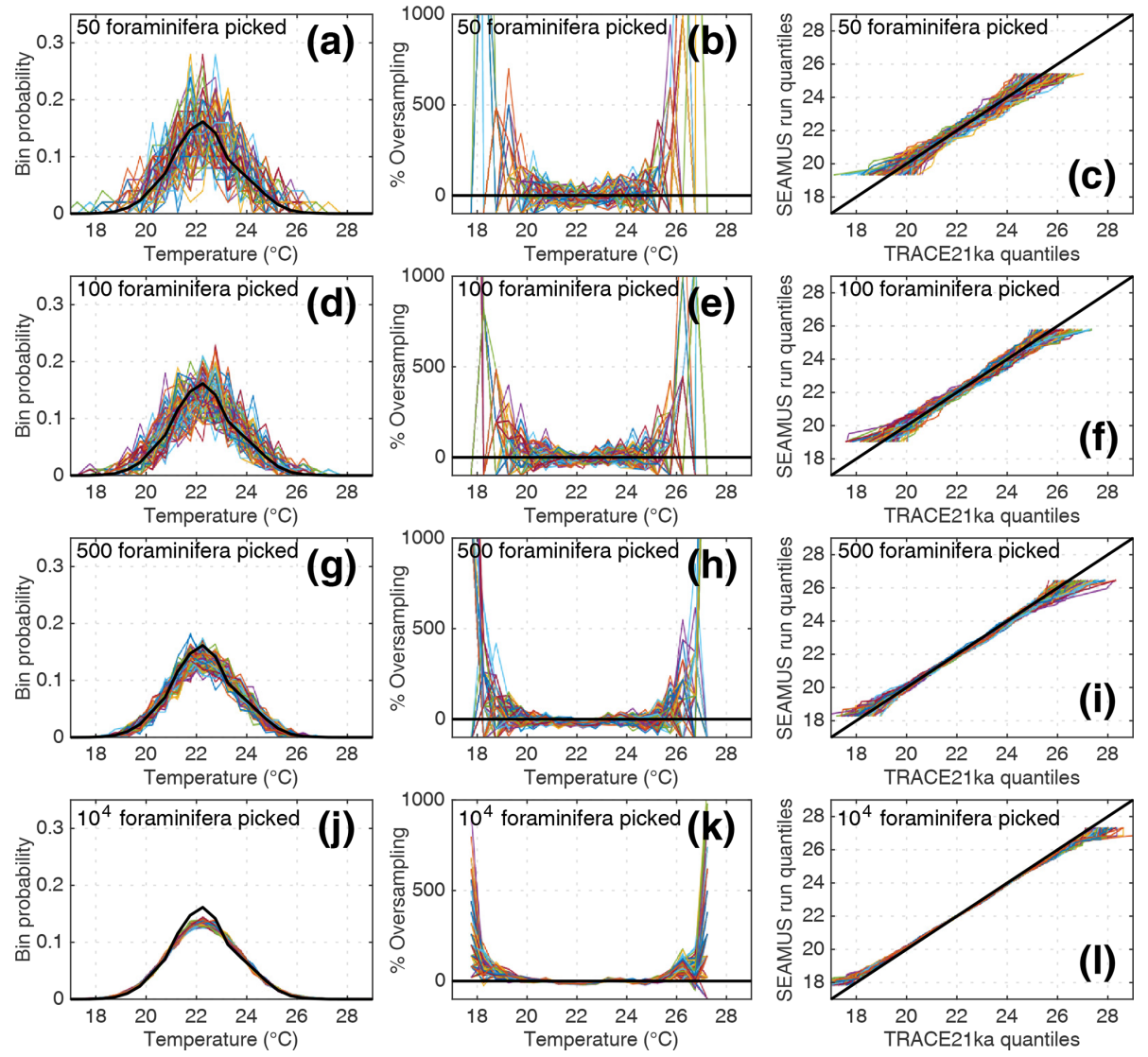

Figure 6. Simulated single foraminifera SST distributions from 100 ensembles of SEAMUS runs, with SAR of $10 \mathrm{~cm} \mathrm{kyr}^{-1}$, BD of $10 \mathrm{~cm}$, $\pm 1^{\circ} \mathrm{C}$ analytical error and constant abundance. In each ensemble, the single foraminifera SST distribution from a single discrete depth with a simulated median age of $17.5 \mathrm{ka}$ is compared to the TRACE-21ka SST distribution for the 18 to $17 \mathrm{ka}$ period. The left panels (a, d, $\mathbf{g}, \mathbf{j})$ show the 100 SEAMUS ensembles as coloured lines in the case of 50,100, 500 and $10^{4}$ randomly picked foraminifera, with the TRACE-21ka SST distribution shown as a black line. The middle panels (b, e, h, k) show the rate of oversampling/undersampling for each of the 100 SEAMUS ensembles (coloured lines) relative to the TRACE-21ka SST distribution (black line) in the case of 50, 100, 500 and $10^{4}$ randomly picked foraminifera. The right panels $(\mathbf{c}, \mathbf{f}, \mathbf{i}, \mathbf{l})$ show Q-Q plots of the 100 SEAMUS ensemble quantiles vs the TRACE-21ka quantiles as coloured lines in the case of 50,100, 500 and $10^{4}$ randomly picked foraminifera, with a perfect $1: 1$ correspondence to TRACE-21ka shown for reference as a black line.

lation characterised not by a uniform distribution of time but an exponential distribution of time with a long tail towards older ages.

Finally, we investigate the influence of temperatureinduced species abundance changes upon IFA-derived SST distributions. Our $10 \mathrm{~cm} \mathrm{kyr}^{-1}$ simulations that have been run using the temperature abundance transfer function in Fig. 2a are shown in Fig. 7 (without analytical noise) and Fig. 8 (with analytical noise). We find that in all cases, the IFA-derived SST distribution is biased towards too warm values when compared to the TRACE-21ka SST distribution (panels a, d, g and j in Figs. 7 and 8). This bias can also be visualised as an oversampling of warmer values (panels $b$, e, h, $\mathrm{k}$ in Figs. 7 and 8), or bias in a Q-Q plot (panels c, f, i, 1 in Figs. 7 and 8). We demonstrate that a species' abundance response to temperature can inherently bias IFA-derived reconstructions of SST distribution, which could have practical consequences for studies in the field. For example, the results in studies that compare IFA-derived SST distributions from significantly differing mean climate states (White et al., 2018; White and Ravelo, 2020), may be (partially) attributable to a species' temperature abundance response to the dominating SST profile associated with the differing climate states. Our results demonstrate the importance of incorporating understanding of past temporal changes of species abundance and how they can be influenced by SST itself. While here we model a theoretical species that is biased towards warmer temperatures, the same principle would hold true for a species biased towards colder temperatures, i.e. 

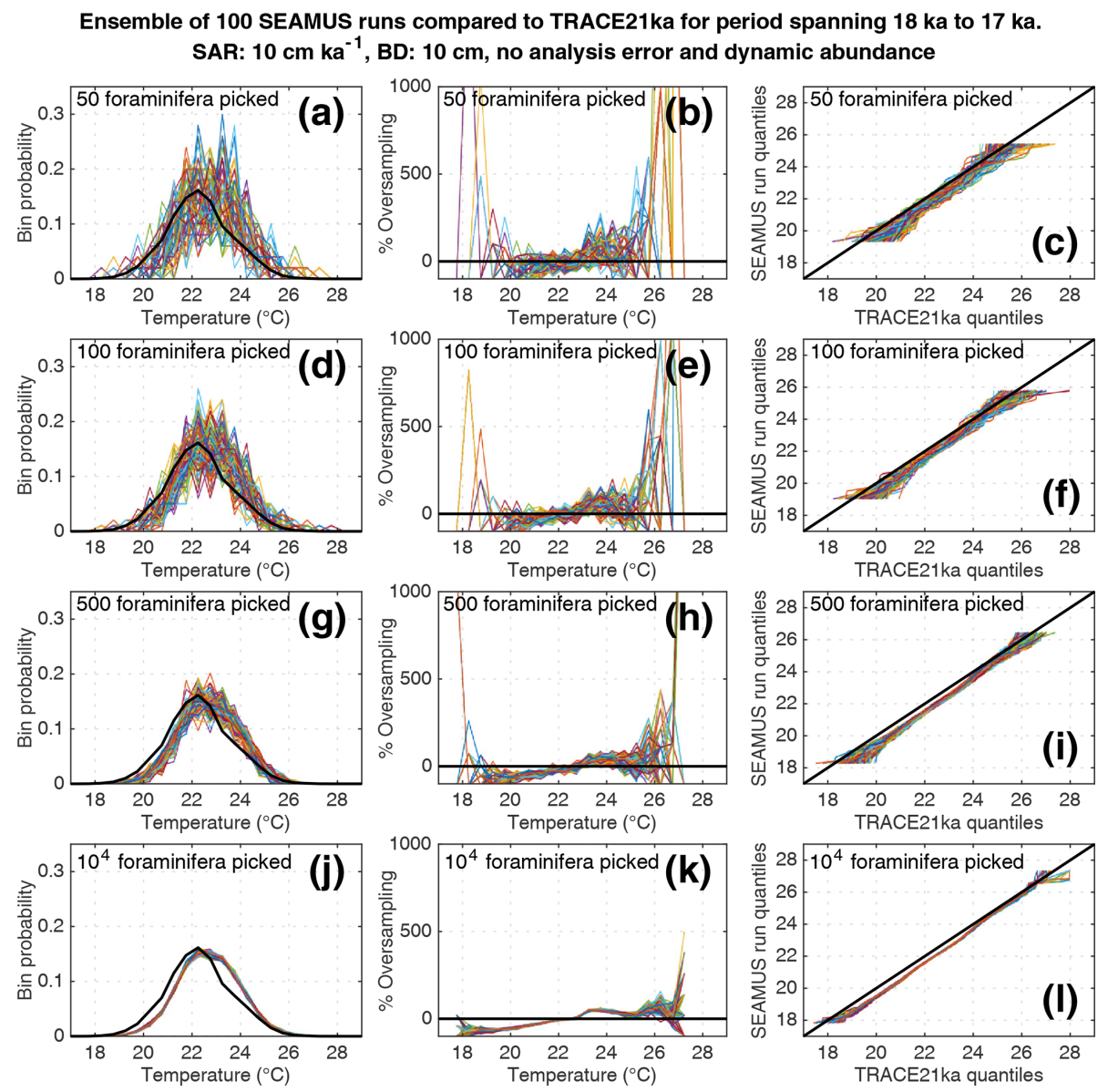

Figure 7. Simulated single foraminifera SST distributions from 100 ensembles of SEAMUS runs, with SAR of $10 \mathrm{~cm} \mathrm{kyr}^{-1}$, BD of $10 \mathrm{~cm}$, no analytical error and dynamic abundance (following Fig. 2a). In each ensemble, the single foraminifera SST distribution from a single discrete depth with a simulated median age of $17.5 \mathrm{ka}$ is compared to the TRACE-21ka SST distribution for the 18 to $17 \mathrm{ka}$ period. The left panels (a, d, $\mathbf{g}, \mathbf{j})$ show the 100 SEAMUS ensembles as coloured lines in the case of 50, 100, 500 and $10^{4}$ randomly picked foraminifera, with the TRACE-21ka SST distribution shown as a black line. The middle panels $(\mathbf{b}, \mathbf{e}, \mathbf{h}, \mathbf{k})$ show the rate of oversampling/undersampling for each of the 100 SEAMUS ensembles (coloured lines) relative to the TRACE-21ka SST distribution (black line) in the case of 50, 100, 500 and $10^{4}$ randomly picked foraminifera. The right panels $(\mathbf{c}, \mathbf{f}, \mathbf{i}, \mathbf{l})$ show Q-Q plots of the 100 SEAMUS ensemble quantiles vs. the TRACE$21 \mathrm{ka}$ quantiles as coloured lines in the case of 50,100, 500 and $10^{4}$ randomly picked foraminifera, with a perfect $1: 1$ correspondence to TRACE-21ka shown for reference as a black line.

the IFA-derived SST distribution could show a bias towards colder temperatures.

\section{Conclusion \& outlook}

Our best-case modelling study reveals a number of challenges inhibiting the efficacy of discrete-depth IFA in producing reconstructions of past SST distribution, the latter of which is paramount in reconstructing, e.g. past ENSO-type climate dynamics. Firstly, we find that bioturbation of sediment archives, combined with typical sample sizes employed in IFA-based studies, can lead to noisy IFA-derived SST distribution reconstructions. This noise leads to poor reproducibility with a potential for artefactual results. We would like to reiterate that our best-case model scenarios are possi- bly not representative for field studies that have been carried out. It is entirely possible that existing studies have been retrieved from areas with a BD that is significantly more or less than the global average of $10 \mathrm{~cm}$. Consequently, our model results may either overstate or understate challenges relevant to IFA at particular locations. We propose, therefore, that studies in the field can improve quantification of the total error on IFA reconstructions at their particular locations using three main approaches: (1) quantification of real-world sedimentological parameters (SAR, BD) and foraminifera parameters (abundance, temperature sensitivity) at the core site. (2) Ensemble-based forward model studies, as detailed in this study using best-case scenarios, can be run using the sediment and foraminifera parameters present at the core site. This approach will help estimate the total stochastic error as- 
Ensemble of 100 SEAMUS runs compared to TRACE21 ka for period spanning $18 \mathrm{ka}$ to $17 \mathrm{ka}$. SAR: $10 \mathrm{~cm} \mathrm{ka}{ }^{-1}, \mathrm{BD}: 10 \mathrm{~cm}, \pm 1^{\circ} \mathrm{C}$ analysis error and dynamic abundance
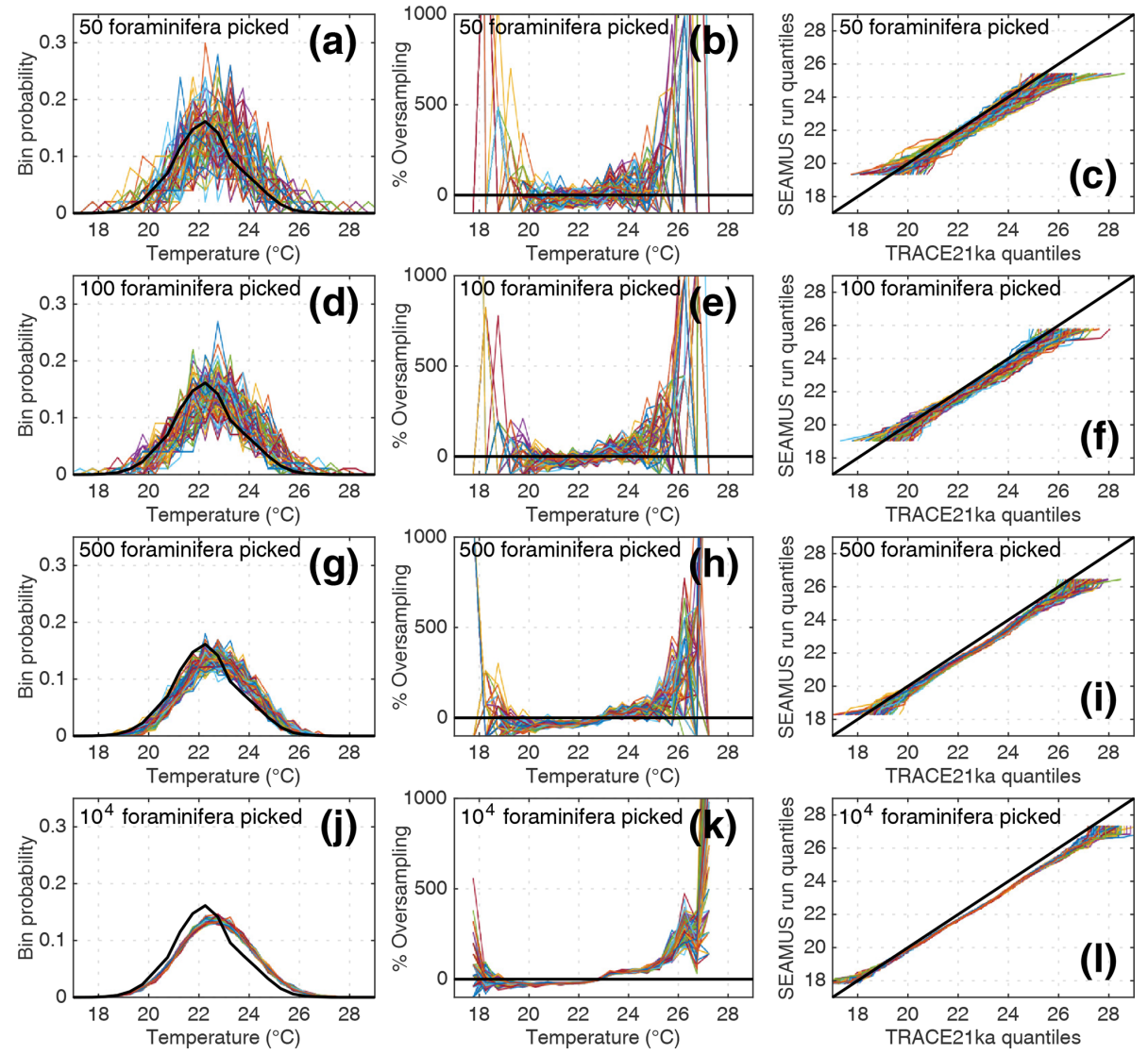

Figure 8. Simulated single foraminifera SST distributions from 100 ensembles of SEAMUS runs, with SAR of $10 \mathrm{~cm} \mathrm{kyr}^{-1}$, BD of $10 \mathrm{~cm}$, $\pm 1{ }^{\circ} \mathrm{C}$ analytical error and dynamic abundance (following Fig. 2a). In each ensemble, the single foraminifera SST distribution from a single discrete depth with a simulated median age of $17.5 \mathrm{ka}$ is compared to the TRACE-21ka SST distribution for the 18 to $17 \mathrm{ka}$ period. The left panels (a, d, g, j) show the 100 SEAMUS ensembles as coloured lines in the case of 50,100, 500 and $10^{4}$ randomly picked foraminifera, with the TRACE-21ka SST distribution shown as a black line. The middle panels $(\mathbf{b}, \mathbf{e}, \mathbf{h}, \mathbf{k})$ show the rate of oversampling/undersampling for each of the 100 SEAMUS ensembles (coloured lines) relative to the TRACE-21ka SST distribution (black line) in the case of 50, 100, 500 and $10^{4}$ randomly picked foraminifera. The right panels $(\mathbf{c}, \mathbf{f}, \mathbf{i}, \mathbf{l})$ show Q-Q plots of the 100 SEAMUS ensemble quantiles vs the TRACE$21 \mathrm{ka}$ quantiles as coloured lines in the case of 50,100,500 and $10^{4}$ randomly picked foraminifera, with a perfect $1: 1$ correspondence to TRACE-21ka shown for reference as a black line.

sociated with the IFA-derived reconstruction. Care must be taken to include uncertainties regarding time-domain estimations of SAR, BD, species abundance and analytical uncertainty. (3) Replication studies in the field (essentially a realworld ensemble approach) to help to further understand the stochastic noise involved with IFA reconstructions.

We furthermore have shown in our best-case study that a species' abundance response to SST can inherently bias IFAderived reconstructions of past SST variability. We propose that the coupling of a single foraminifera sediment model approach to foraminifera ecological models (Lombard et al., 2011; Roche et al., 2018; Metcalfe et al., 2020) could further help to constrain the total uncertainty associated with IFAderived SST reconstructions.
We have also demonstrated that observed or model SST from uniform periods of time (as humans are accustomed to using) cannot directly be compared to IFA-derived SST, which is retrieved from a population with an age distribution characterised by an exponential distribution with a long tail towards older ages. Subsequently, we propose that researchers adjust observational or model SST data to integrate an exponential representation of time when comparing to IFA-derived SST.

Code availability. Scripts and instructions for reproducing the ensemble simulations in this study are available for download from Lougheed and Metcalfe (2022, https://doi.org/10.5281/zenodo. 6171827). 


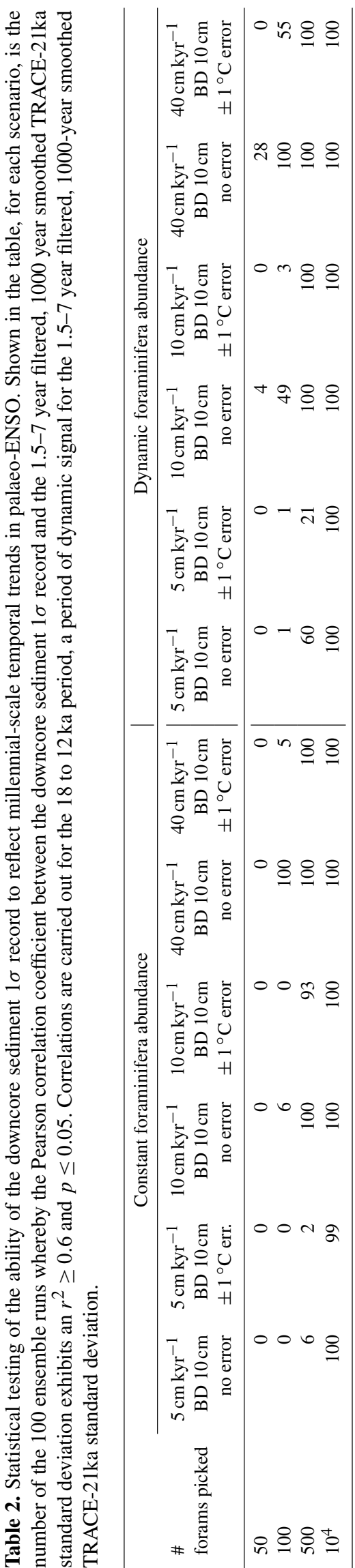

Author contributions. BCL and BM conceived the study. BCL executed the model runs and wrote the paper, with input from BM.

Competing interests. The contact author has declared that neither they nor their co-author has any competing interests.

Disclaimer. Publisher's note: Copernicus Publications remains neutral with regard to jurisdictional claims in published maps and institutional affiliations.

Acknowledgements. The Swedish National Infrastructure for Computing (SNIC) at the Uppsala Multidisciplinary Centre for Advanced Computational Science (UPPMAX) provided computing resources for parallel ensemble runs. Jesper Sjolte and Feng He are thanked for help in locating the correct TRACE-21ka model run file. The authors thank the reviewers and editor for their valuable feedback.

Financial support. This research was supported by the Swedish Research Council (Vetenskapsrådet; grant no. 2018-04992).

Review statement. This paper was edited by Hiroshi Kitazato and reviewed by three anonymous referees.

\section{References}

Bard, E.: Paleoceanographic implications of the difference in deepsea sediment mixing between large and fine particles, Paleoceanography, 16, 235-239, 2001.

Berger, W. H. and Heath, G. R.: Vertical mixing in pelagic sediments, J. Mar. Res., 26, 134-143, 1968.

Boudreau, B. P.: Mean mixed depth of sediments: The wherefore and the why, Limnol. Oceanogr., 43, 524-526, https://doi.org/10.4319/lo.1998.43.3.0524, 1998.

Dolman, A. M. and Laepple, T.: Sedproxy: a forward model for sediment-archived climate proxies, Clim. Past, 14, 1851-1868, https://doi.org/10.5194/cp-14-1851-2018, 2018.

Dryden, A. L.: Accuracy in Percentage Representation of Heavy Mineral Frequencies, P. Natl. Acad. Sci. USA, 17, 233-238, https://doi.org/10.1073/pnas.17.5.233, 1931.

Ford, H. L., Ravelo, A. C., and Polissar, P. J.: Reduced El NinoSouthern Oscillation during the Last Glacial Maximum, Science, 347, 255-258, https://doi.org/10.1126/science.1258437, 2015.

Fraass, A. J. and Lowery, C. M.: Defining uncertainty and error in planktic foraminiferal oxygen isotope measurements: Uncertainty in Foram Oxygen Isotopes, Paleoceanography, 32, 104 122, https://doi.org/10.1002/2016PA003035, 2017.

Ganssen, G. M., Peeters, F. J. C., Metcalfe, B., Anand, P., Jung, S. J. A., Kroon, D., and Brummer, G.-J. A.: Quantifying sea surface temperature ranges of the Arabian Sea for the past 20000 years, Clim. Past, 7, 1337-1349, https://doi.org/10.5194/cp-71337-2011, 2011 
Glaubke, R. H., Thirumalai, K., Schmidt, M. W., and Hertzberg, J. E.: Discerning Changes in High-Frequency Climate Variability Using Geochemical Populations of Individual Foraminifera, Paleoceanogr. Paleocl., 36, e2020PA004065, https://doi.org/10.1029/2020PA004065, 2021.

He, F.: Simulating transient climate evolution of the last deglaciation with CCSM 3, PhD thesis, University of Winsconsin, Madison, Madison, WI, USA, 2011.

Henderiks, J., Freudenthal, T., Meggers, H., Nave, S., Abrantes, F., Bollmann, J., and Thierstein, H. R.: Glacial-interglacial variability of particle accumulation in the Canary Basin: a time-slice approach, Deep-Sea Res. Pt. II, 49, 3675-3705, https://doi.org/10.1016/S0967-0645(02)00102-9, 2002.

Khider, D., Stott, L. D., Emile-Geay, J., Thunell, R., and Hammond, D. E.: Assessing El Niño Southern Oscillation variability during the past millennium, Paleoceanography, 26, PA3222, https://doi.org/10.1029/2011PA002139, 2011.

Killingley, J. S., Johnson, R. F., and Berger, W. H.: Oxygen and carbon isotopes of individual shells of planktonic foraminifera from Ontong-Java plateau, equatorial pacific, Palaeogeogr. Palaeocl., 33, 193-204, https://doi.org/10.1016/0031-0182(81)90038-9, 1981.

Koutavas, A. and Joanides, S.: El Niño-Southern Oscillation extrema in the Holocene and Last Glacial Maximum, Paleoceanography, 27, PA4208, https://doi.org/10.1029/2012PA002378, 2012.

Koutavas, A., deMenocal, P. B., Olive, G. C., and LynchStieglitz, J.: Mid-Holocene El Niño-Southern Oscillation (ENSO) attenuation revealed by individual foraminifera in eastern tropical Pacific sediments, Geology, 34, 993-996, https://doi.org/10.1130/G22810A.1, 2006.

Leduc, G., Vidal, L., Cartapanis, O., and Bard, E.: Modes of eastern equatorial Pacific thermocline variability: Implications for ENSO dynamics over the last glacial period, Paleoceanography, 24, PA3202, https://doi.org/10.1029/2008PA001701, 2009.

Liu, Z., Lu, Z., Wen, X., Otto-Bliesner, B. L., Timmermann, A., and Cobb, K. M.: Evolution and forcing mechanisms of El Niño over the past 21,000 years, Nature, 515, 550-553, https://doi.org/10.1038/nature13963, 2014.

Lombard, F., Labeyrie, L., Michel, E., Bopp, L., Cortijo, E., Retailleau, S., Howa, H., and Jorissen, F.: Modelling planktic foraminifer growth and distribution using an ecophysiological multi-species approach, Biogeosciences, 8, 853-873, https://doi.org/10.5194/bg-8-853-2011, 2011.

Lougheed, B. C.: SEAMUS (v1.20): a $\Delta^{14}$ C-enabled, singlespecimen sediment accumulation simulator, Geosci. Model Dev., 13, 155-168, https://doi.org/10.5194/gmd-13-155-2020, 2020.

Lougheed, B. C. and Metcalfe, B.: Simulation ensembles for: "Testing the effect of bioturbation and species abundance upon discrete-depth individual foraminifera analysis", Zenodo [code], https://doi.org/10.5281/zenodo.6171827, 2022.

Metcalfe, B., Lougheed, B. C., Waelbroeck, C., and Roche, D. M.: A proxy modelling approach to assess the potential of extracting ENSO signal from tropical Pacific planktonic foraminifera, Clim. Past, 16, 885-910, https://doi.org/10.5194/cp-16-8852020, 2020.

Oba, T. and Uomonoto, K.: Oxygen and Carbon Isotopic Ratios of Planktonic Foraminifera in Sediment Traps JT-01 and JT-02, Gekkan Kaiyō, 21, 239-246, 1989.
Olson, P., Reynolds, E., Hinnov, L., and Goswami, A.: Variation of ocean sediment thickness with crustal age, Geochem. Geophy., 17, 1349-1369, https://doi.org/10.1002/2015GC006143, 2016.

Patterson, R. T. and Fishbein, E.: Re-examination of the statistical methods used to determine the number of point counts needed for micropaleontological quantitative research, J. Paleontol., 63 , 245-248, https://doi.org/10.1017/S0022336000019272, 1989.

Peng, T.-H., Broecker, W. S., and Berger, W. H.: Rates of benthic mixing in deep-sea sediment as determined by radioactive tracers, Quaternary Res., 11, 141-149, 1979.

Pisias, N. G.: Geologic time series from deep-sea sediments: Time scales and distortion by bioturbation, Mar. Geol., 51, 99-113, 1983.

Pracht, H., Metcalfe, B., and Peeters, F. J. C.: Oxygen isotope composition of the final chamber of planktic foraminifera provides evidence of vertical migration and depth-integrated growth, Biogeosciences, 16, 643-661, https://doi.org/10.5194/bg-16-6432019, 2019.

Roche, D. M., Waelbroeck, C., Metcalfe, B., and Caley, T.: FAME (v1.0): a simple module to simulate the effect of planktonic foraminifer species-specific habitat on their oxygen isotopic content, Geosci. Model Dev., 11, 3587-3603, https://doi.org/10.5194/gmd-11-3587-2018, 2018.

Rongstad, B. L., Marchitto, T. M., Marks, G. S., Koutavas, A., Mekik, F., and Ravelo, A. C.: Investigating ENSORelated Temperature Variability in Equatorial $\mathrm{Pa}-$ cific Core-Tops Using $\mathrm{Mg} / \mathrm{Ca}$ in Individual Planktic Foraminifera, Paleoceanogr. Paleocl., 35, e2019PA003774, https://doi.org/10.1029/2019PA003774, 2020.

Rustic, G. T., Koutavas, A., Marchitto, T. M., and Linsley, B. K.: Dynamical excitation of the tropical Pacific Ocean and ENSO variability by Little Ice Age cooling, Science, 350, 1537-1541, 2015.

Schiffelbein, P.: Effect of benthic mixing on the information content of deep-sea stratigraphical signals, Nature, 311, 651-653, https://doi.org/10.1038/311651a0, 1984.

Schiffelbein, P. and Hills, S.: Direct assessment of stable isotope variability in planktonic foraminifera populations, Palaeogeogr. Palaeocl., 48, 197-213, https://doi.org/10.1016/00310182(84)90044-0, 1984.

Scussolini, P., van Sebille, E., and Durgadoo, J. V.: Paleo Agulhas rings enter the subtropical gyre during the penultimate deglaciation, Clim. Past, 9, 2631-2639, https://doi.org/10.5194/cp-92631-2013, 2013.

Spero, H. J. and Williams, D. F.: Evidence for seasonal low-salinity surface waters in the Gulf of Mexico over the last 16,000 years, Paleoceanography, 5, 963-975, https://doi.org/10.1029/PA005i006p00963, 1990.

Thirumalai, K., Partin, J. W., Jackson, C. S., and Quinn, T. M.: Statistical constraints on El Niño Southern Oscillation reconstructions using individual foraminifera: A sensitivity analysis, Paleoceanography, 28, 401-412, https://doi.org/10.1002/palo.20037, 2013.

Thirumalai, K., DiNezio, P. N., Tierney, J. E., Puy, M., and Mohtadi, M.: An El Niño Mode in the Glacial Indian Ocean?, Paleoceanogr. Paleocl., 34, 1316-1327, https://doi.org/10.1029/2019PA003669, 2019.

Trauth, M. H.: TURBO: a dynamic-probabilistic simulation to study the effects of bioturbation on paleoceanographic time series, 
Comput. Geosci., 24, 433-441, https://doi.org/10.1016/S00983004(98)00019-3, 1998.

Trauth, M. H.: TURBO2: A MATLAB simulation to study the effects of bioturbation on paleoceanographic time series, Comput. Geosci., 61, 1-10, https://doi.org/10.1016/j.cageo.2013.05.003, 2013.

Trauth, M. H., Sarnthein, M., and Arnold, M.: Bioturbational mixing depth and carbon flux at the seafloor, Paleoceanography, 12, 517-526, 1997.
White, S. M. and Ravelo, A. C.: Dampened El Niño in the Early Pliocene Warm Period, Geophys. Res. Lett., 47, e2019GL085504, https://doi.org/10.1029/2019GL085504, 2020.

White, S. M., Ravelo, A. C., and Polissar, P. J.: Dampened El Niño in the Early and Mid-Holocene Due To Insolation-Forced Warming/Deepening of the Thermocline, Geophys. Res. Lett., 45, 316326, https://doi.org/10.1002/2017GL075433, 2018. 